\title{
BM] open Risk perception of sexually transmitted infections and HIV in Nigerian commercial sex workers living in Barcelona: a study protocol
}

To cite: Coma Auli N, MejíaLancheros C, Berenguera A, et al. Risk perception of sexually transmitted infections and HIV in Nigerian commercial sex workers living in Barcelona: a study protocol. BMJ Open 2013:3:e003345

doi:10.1136/bmjopen-2013003345

- Prepublication history for this paper is available online. To view these files please visit the journal online (http://dx.doi.org/10.1136/ bmjopen-2013-003345).

Received 4 June 2013 Accepted 20 June 2013

\footnotetext{
${ }^{1}$ Unitat de medicina tropical i salut internacional Drassanes-Vall d'Hebron. Institut Català de la Salut, Barcelona, Spain

${ }^{2}$ Department of Paediatrics, Obstetrics, Gynaecology and Preventive Medicine, Universitat Autònoma de Barcelona, Barcelona, Spain ${ }^{3}$ Institut d'Investigació en Atenció Primària (IDIAP Jordi Gol), Barcelona, Spain

${ }^{4}$ Investigador Associat de la Universitat Autònoma de Barcelona, Bellaterra (Cerdanyola del Vallès), Spain

${ }^{5}$ Unitat d'infeccions de transmissió sexual Drassanes-Vall d'Hebron. Institut Català de la Salut, Barcelona, Spain
}

Correspondence to Enriqueta Pujol-Ribera; epujol@idiapjgol.org

\author{
Núria Coma Auli, ${ }^{1}$ Cília Mejía-Lancheros, ${ }^{2}$ Anna Berenguera, ${ }^{3,4}$ Martí Vall Mayans, ${ }^{5}$ \\ Maider Arando Lasagabaster, ${ }^{5}$ Enriqueta Pujol-Ribera ${ }^{3,4}$
}

\section{ABSTRACT \\ Introduction: Sexually transmitted infections (STIS) and HIV are a serious global public health issue. These diseases are largely preventable, as they are directly and indirectly associated with potentially modifiable factors, including socioeconomic conditions. Sexual transmission is responsible for over $75 \%$ of new HIV infections worldwide. Moreover, commercial sex workers and their clients are two of the groups at the highest risk of acquiring and transmitting these infectious diseases, due to an extensive number of sexual encounters and the various factors related to commercial sex situations. This qualitative study aims to deepen the understanding of the risk perception of STIs and HIV and their associated factors in Nigerian commercial sex workers in the city of Barcelona.}

Methods and analysis: This is a qualitative, descriptive, interpretive study based on a social constructivist and phenomenological perspective conducted on a saturated sample of Nigerian commercial sex workers in the city of Barcelona. Data will be collected through semistructured individual and triangular group interviews. Information will be examined using a sociological discourse analysis, allowing us to understand the social and individual factors related to the risk perception of STIS and HIV in commercial sex workers.

Discussion: Qualitative studies are an important element in identifying individual, social and contextual factors directly or indirectly related to the health/ disease process. This qualitative study will provide essential knowledge to improve health promotion, prevention strategies and effective management of STIs both for commercial sex workers and their clients.

Ethics: This study has been approved by the clinical research ethics committee (CEIC) of IDIAP Jordi Gol in Barcelona, 2012.

\section{INTRODUCTION}

Sexually transmitted infections, HIV and commercial sex

Sexually transmitted infections (STIs) and HIV are largely preventable diseases, as they result directly and indirectly from potentially modifiable factors such as those related to cultural, individual and socioeconomic conditions and access to health services.

The practice of prostitution or commercial sex is something that has existed or been identified in all societies throughout history. ${ }^{1} 2$ According to the report by the Joint United Nations Programme on HIV-AIDS (UNAIDS), ${ }^{3}$ there are approximately 34 million people infected with HIV worldwide, and it emphasises that commercial sex workers (CSWs) are one of the groups at the greatest risk of acquiring and transmitting STIs/HIV. The report also underlines that there is currently a serious need for effective strategies and measures to raise awareness and improve the healthcare, control, treatment and social support networks of CSWs and their clients to reduce the burden of morbidity, mortality and disability that STIs/HIV cause(s) to individuals, society and health systems.

The WHO suggests that sexual transmission is responsible for over $75 \%$ of new HIV infections occurring globally, ${ }^{4}{ }^{5}$ and it highlights that CSWs and their clients have a higher risk of contracting HIV due to the extensive number of sexual encounters and to the factors directly or indirectly related to commercial sex situations. It also states that CSWs who work illegally are the population group most susceptible to these infections. ${ }^{6}$ Nevertheless, there is also evidence suggesting that debt dependency, low pay and poor living conditions may jeopardise the health and safety of CSWs, and it has been reported that when CSWs have control over their own working situation and insist on safer sex relations, the risk of and vulnerability to HIV can be significantly reduced. ${ }^{78}$

According to the Centre for Epidemiological Studies on STIs/HIV/AIDS (CEEISCAT), HIV 
prevalence was low (2.5\%) among CSWs in Catalonia in 2007 , when the figure was significantly higher among Spaniards than among immigrants $(8.9 \%$ vs $1.5 \%)$. For the case of STIs, there was an overall prevalence of $8.8 \%$ of Chlamydia trachomatis and $1 \%$ of Neisseria gonorrhoeae, however, a significant increase was observed in the prevalence of $C$ trachomatis in African women with respect to the results reported in $2005 .^{9}$ According to the Public Health Agency of Barcelona, ${ }^{10}$ in the city of Barcelona in 2008, there was an incidence rate of HIV of 34.60 in men and 3.60 in women; of gonococcus infection of 25.95 in men and 2.11 in women; of lymphogranuloma venereum of 1.90 in men; and of syphilis of 2.30 in men and 21.40 in women (all rates were calculated per 100000 people). Meanwhile, a study performed in Catalonia by Folch $e t a l^{11}$ reported the following disease prevalence among 400 female CSWs (including 130 African women): $1.8 \%$ of HIV infection, $5.5 \%$ of $C$ trachomatis and $0.5 \%$ of $N$ gonorrhoeae.

There are no specified figures on the number of people involved in prostitution in the city of Barcelona; however, prostitution can be seen in many areas of the city, both in the city centre and in the outskirts.

\section{Risk perception}

It is extremely important in terms of public health to conduct studies that seek to explore, identify, understand, describe and analyse the perception, knowledge and behaviours of CSWs as well as the associated sociopolitical and cultural factors and the role they play in the risk of acquiring and transmitting STIs/HIV. In epidemiology, risk expresses the probability that an eventsuch as becoming ill or dying after exposure to certain factors (called risk factors) - will occur; moreover, this risk may be perceived differently from different perspectives, depending on each individual and on his or her environment. ${ }^{12-14}$ According to the literature, risk perception is a complex multifactorial process built on the experiences that a person undergoes during the course of his or her life which are directly or indirectly influenced by socioeconomic, political and cultural contexts. ${ }^{15}$ Some authors have proposed different theories about the mechanism that may be linked to the risk perception process, such as behaviours and skills, ${ }^{16}$ health beliefs, ${ }^{17}$ social learning, ${ }^{18} 19$ reasoned actions, planned conducts, behaviour and self-control. ${ }^{20-22}$ Some of these mechanisms or conditions may influence or be linked to the perception that CSWs have about exposure to and acquisition, transmission and treatment of STIs and HIV. Some studies analysing the risk perception of STIs and HIV in CSWs have found that having knowledge about HIV/AIDS influences whether or not risky behaviours are adopted and that risk perception is also affected by misconceptions that CSWs have, even though they are aware of being to some extent exposed to these diseases. $^{12} 2324$

Studies performed on sex workers (2009-2010) in Spain have shown that even when these individuals had knowledge about HIV, modes of transmission, consequences of and their high vulnerability, they performed risky behaviours. They attributed their lack of condom use to socioeconomic reasons, especially when they were better paid for unprotected sexual services. ${ }^{25} 26$ Moreover, it has been reported that for some CSWs, having an STI is a source of concern, because it greatly limits their economic benefits; as a result, they accept the risk of being infected as a consequence of their work. ${ }^{27}$ Furthermore, many CSWs are aware that they can get HIV through sexual contact, but they only associate the risk with a work setting and not with a private sexual context (partner). ${ }^{28}$

Taking into account that research on the risk perception of STIs/HIV in CSWs is scarce and that these diseases currently have a high impact on public health in developed as well as undeveloped countries, it is necessary to address the factors associated with these health conditions by using different investigative techniques, including quantitative research, to reorient and complement prevention, control and treatments programmes, thus achieving a greater health impact on the highest risk individuals.

\section{Research proposal}

This qualitative study aims to explore the risk perception of STIs and HIV and their associated factors in Nigerian commercial sex workers in the city of Barcelona. It seeks to provide essential knowledge to improve health promotion, prevention strategies and effective management of sexually transmitted infections both for commercial sex workers and their clients.

We are initially interested in Nigerian CSWs, because they are widely present in the city of Barcelona, many of them are frequent users of the NGO services operating in the city centre and some research team members have professional contact with this population group, affording us a closer relationship with participants and familiarity with participants' situations. In addition, this study could allow for future comparisons with other studies performed on CSWs in Nigeria. ${ }^{29}$

\section{Overall objective}

To explain the knowledge, attitudes and behaviours linked to the risk perception of contracting and transmitting STIs and HIV of Nigerian CSWs in Barcelona using a qualitative study based on a social constructivist perspective during a 1-year period.

\section{Specific objectives}

1. To explore knowledge and meanings concerning STIs and HIV in Nigerian female CSWs who practice their profession in the city of Barcelona.

2. To identify the attitudes and behaviours of these women with respect to STI and HIV prevention during their work and private life.

3. To understand the risk perception of contracting and transmitting STIs and HIV in this group of CSWs. 
4. To learn about the socioeconomic and cultural factors influencing these women's exposure to STI and HIV risk.

5. To recognise which elements of multisectoral programmes these women find useful in acquiring knowledge and adopting attitudes, behaviours and actions intended to prevent exposure to and spread of STI and HIV.

\section{METHODS AND ANALYSIS \\ Design}

This is a qualitative, descriptive, interpretive study based on the social constructivist and phenomenological perspective, as it aims to describe the knowledge, attitudes and behaviours for preventing STIs/HIV in Nigerian CSWs. It also seeks to understand and interpret what the risk of contracting and transmitting these infections means for this population group as a result of their experiences throughout their lives and taking into account socioeconomic, cultural and political factors from an individual and a global context (work access to social health, available social services, social integration, etc).

\section{Study setting}

The study will be conducted in the city of Barcelona and it is estimated to last for a period of 1 year.

\section{Study populations}

We will invite Nigerian CSWs over 18 years old to take part in the study. We will include those persons who voluntarily agree to participate and sign the specific consent form for the study.

\section{Sample design and participant selection strategy}

Since we want to obtain a framework explaining the phenomenon under study, participants will be selected based on a priori defined profiles; therefore, sampling will be intentional, rational and theoretical. To ensure that we promote the maximum variety of discourses among study participants, we will take the following variables into account: different age ranges, with and without a partner, with and without children, and participating and not participating in training activities aimed to increase awareness and prevention of STIs/ HIV. We will consider the time participants have been practicing their profession and residing in Spain as complementary variables.

Participants will be recruited through mediating agents such as health workers, social partners and NGOs that have direct or indirect contact with the target population (Nigerian CSWs).

\section{Data collection methods}

The data will initially be collected through semistructured individual interviews (box 1). This technique will ensure a more intimate, confidential and safe environment for study participants, which will in turn make them feel more comfortable and remove any pressure, thus encouraging spontaneous responses matching their perceptions of the phenomenon under study. In a second phase, triangular groups will be formed in order to obtain more open discourses and promote saturation of the information. Groups will use interactive and dynamic questions led by the moderator in triangular group interviews, thus allowing us to obtain complementary information. ${ }^{30}$

Respondents will be contacted through health workers participating in the study. Once women have voluntarily agreed to take part in the study and individual and triangular interviews have been conducted, researchers will explain the purpose of the study and the confidentiality of the collected data. Participants will be asked to sign written informed consent forms in order to record the interview and publish the results. Individual and triangular session interviews will last for approximately 60$90 \mathrm{~min}$. Interviews will be conducted by the study researchers. Individual interviews will be taped, while triangular interviews will be video recorded.

\section{Analysis of the information}

We will conduct a sociological discourse analysis to describe and interpret the contents expressed both individually and in triangular groups. Analysing discourse as part of social processes makes it possible to understand the social context of the aspects being studied. Discourse meanings will be identified by gradually and systematically reading and re-reading all the information obtained through the interviews.

The following procedure will be used to analyse speech:

1. Collect data: conduct interviews and make audio or video recordings of them.

2. Team researchers will create verbatim and systematic transcripts of the obtained narrative data, protecting primary versions of the interviews and masking the personal identity data of each participant.

3. Read and re-read the text corpus to define initial preanalytical intuitions and explain the whole text.

4. Analyse the social status from which the woman is speaking. We will analyse the stories according to the social condition and the context in which they were produced, taking into account the order in which they occur in conversations.

5. Identify symbolic configurations, thus generating a comprehensive understanding of the text according to the research objectives and the context. Speech will be organised according to narrative axes.

6. Establish semantic configurations (text encoding) to conduct the specific internal analysis of the text using semantic attractors, and develop a new text with the results.

7. Interpret results: we will search for elements which interact with both individual interviews and triangular group interviews and we will use them to 


\section{Box 1 Interview model}

A. General presentation of interviewers, research and research objectives. Afterwards, participants are asked to give informed consent to audio and/or video recording.

B. Interview topics:

1. Knowledge about STIS/HIV/AIDS

a. In your opinion, what are/is STIS/HIV/AIDS?

b. Do you know how STIS/HIV/AIDS are/is transmitted?

c. Are certain people at higher risk for these infections?

d. What kinds of behaviours increase the likelihood of transmission of STIS/HIV/AIDS?

e. How can you prevent these infections?

f. Can they be treated?

g. Do you receive or have you received in the past information on STIS/HIV/AIDS from any institutions or organisations?

2. Behaviour and risk perception

a. Do you think your job is dangerous in terms of contracting or transmitting STIS/HIV?

b. Do you use any measures to prevent direct sexual contact with clients? Which ones? For example: condoms, gels, watersoap, disinfectants, other (which?)

c. Do you use a regular hygiene measure after (vaginal, oral or anal) sexual contact? For example: ovules, soap, water, disinfectant...

d. Which sexual services are you most often requested?

e. Are there any sexual requests from your customers which you refuse?

f. Do you use or have you used in the past any protection when you have sex with your partner or spouse?

g. Do you use any substances or drugs, such as heroin, alcohol, cocaine, ecstasy, marijuana, amphetamines etc., during your sexual services?

h. Do you think that offering sexual services in Barcelona is different from doing so in your own country?

3. Socioeconomic, political and cultural issues associated with prostitution and limited access to health services, social services and social integration

a. Since you have been in Barcelona, do you think your life has changed with respect to the life you had in your own country?

b. Do you offer your services independently (autonomously) or have intermediaries?

c. What is your least favourite thing about working in the Raval?

d. Have you received any health services in Barcelona?

e. Have you received any social assistance?

f. Have you had any problems with law enforcement?

g. Would you like for your work to become regulated, monitored and recognised by institutions and society in general?

h. What proposals would you make to public organisations to improve your situation?

i. How do you imagine your future in 3 years?

C. Closing speech: The interviewer will thank each participant for her willingness and time and will then summarise what the participant has said. The participant will also be asked if she wants to add any more comments or confirm, expand upon or clarify any information.

construct explanations, hypotheses and theories about perceived risk and the factors that shape or influence it in the group of Nigerian CSWs. The study will be interpreted from both an individual and global standpoint that will allow us to develop the explanatory framework. ${ }^{31}$

\section{Rigour and quality criteria}

This investigation will be based on the following rigour and quality criteria:

1. Explicit and detailed review of each research phase.

2. Explicit reflection on the design of the sample during the entire recruitment process. We will make every effort to ensure that the selected sample favours the credibility and transferability of the data. Participants will be recruited through health and social workers who regularly work with this population group.

3. Individual and group interviews will have topic guides to help collect information systematically. Researchers will use a field journal. Interviews will be audio or video recorded and transcribed systematically and verbatim. This strategy will help us give the data more credibility and make data easier to verify.

4. The first interviews will be analysed manually by two independent analysts. Afterwards, we will examine the similarities, differences and complementarily between the results obtained to thus establish the symbolic and semantic configurations to be used for the rest of the analyses.

5. Test results will be reviewed by external consultants, experts in qualitative research, to verify their quality and rigour. This strategy will also increase their credibility, verifiability and relevance.

6. Once obtained, preliminary analyses will be subjected to verification by study participants so as to confirm results or reconsider their analysis and interpretation.

\section{Difficulties and limitations of the study}

Some of the difficulties we may encounter when conducting this study will relate to 
1. Recruitment of volunteers to participate in the study: CSWs are a population group stigmatised by society for a variety of reasons, including their profession, origin and social conditions, so it is likely that not all of them will agree to be interviewed. However, women invited to participate in the study will at all times be accompanied by the health worker and will receive a detailed explanation of the purpose, applicability and usefulness of the study.

2. Financial compensation: In a previous attempt to carry out a similar study, the research team had no opportunity to interview CSWs, because some of them asked for financial compensation for being interviewed. The research team members believe that participation in the study must be voluntary and without significant financial incentives. The detailed explanation of the project and its usefulness, coupled with the relationship of trust between the target population and the health worker, will help encourage participation without compensation.

3. Language difficulties: Even though this population group works and lives in Barcelona, some of them do not speak Catalan or Spanish well enough to conduct valid and complete interviews. Some of the interviews may need to be performed in English, although it is possible that some of them do not speak this language well enough either (depending on which area of Nigeria the participant is from). For this reason, the collaboration of mediating agents in the project is essential to facilitate understanding of the participants' discourses.

\section{ETHICS AND DISSEMINATION}

This study was designed following the recommendations of the declaration of Helsinki and the guidelines for Good Practice in Primary Care Research of the Institute for Research in Primary Care Jordi Gol (IDIAP) Barcelona. Participants must sign an informed consent form and grant permission for audio and video recording before individual and triangular group interviews are conducted. Researchers are required to maintain confidentiality and anonymity of the personal information of all study participants, in accordance with Spanish Data Protection Act 15/1999. Material from interviews and video recordings and transcripts will be eliminated once the study is complete. Transcripts will be made by study investigators assisted by trained professionals in this field, and anonymity will be maintained throughout the entire process. Citations will be identified using codes that do not allow respondents to be identified. Furthermore, this study has been approved by the Clinical Research Ethics Committee (CEIC) of IDIAP Jordi Gol in Barcelona.

\section{Scientific and social interest of the project}

The scientific interest of this research project is based on the need to increase knowledge about the perceived risk of Nigerian CSWs working in the city of Barcelona. It seeks to understand how the perception of risk is built from a multidimensional vision by interpreting responses made by the women in this group. It is essential to know the social environment and understand the risk perception concerning STIs/HIV of the groups that are most exposed in order to design more suitable, acceptable, sustainable and effective educational and preventive interventions and to control these diseases based on the actual needs of CSWs and their clients. It is also crucial to promote the empowerment of people engaged in commercial sex and to motivate a social change in this evident phenomenon.

The interest in this project is justified by the fact that there are no similar studies conducted in this context. The results of the work may significantly improve multisectoral services aimed at this group and enhance the control of STIs/HIV, which are a great public health concern with a large social component.

\section{Dissemination of study results}

The experiences, self-criticism and contribution of CSWs are an important source of knowledge and awareness that we are responsible for making known. Research results will be disseminated in various media in order to reach different audiences, including scientists, social and political institutions, health agencies, NGOs and the study population (CSWs), who basically have the largest stake in the project and who will benefit most from the results.

\section{DISCUSSION}

Most research on STIs/HIV is conducted using quantitative studies. These kinds of studies are important for advancing the knowledge, treatment and control of these infections. However, it is also essential to understand living conditions, human interactions and behaviours, conducts, etc, as all these factors are directly or indirectly related to the genesis, transmission, treatment and control of these infections. There is a strong association between these infections and socioeconomic and political factors, an association which is even more pronounced when considering a vulnerable group like CSWs.

Qualitative studies are highly valuable and play a supplementary role when it comes to identifying individual, social and contextual factors, and they are essential for improving health promotion and addressing effective strategies to prevent, treat and manage these infections, both in CSWs and their clients and in the general population.

We believe that this study can provide useful knowledge in the control of STIs/HIV in a high-risk population group (CSWs) and its users, even though the results may not be transferable to the general population or to other contexts. Another limitation of this study is that there are no Nigerians on the research team; however, 
we will contact various information sources in order to better understand this group. Despite these limitations, we will use a rigorous methodology design to ensure the study's internal and external validity.

The concept of triangulation in social sciences assumes that the greater the variety of methodologies, data and researchers used in analysing a specific problem the more reliable the final results will be. The basis of these techniques comes from the idea that when a hypothesis survives the confrontation of different methodologies, it has a greater degree of validity than if it only comes from one. In this study, we will apply the quality criteria of qualitative research: triangulation of methodologies using different sources and respondents, triangulation of researchers (different researchers analysing the same sources of information) and triangulation of results (participants will see the results of transcriptions in order to verify content and conclusions).

We, as a research team, believe that health services should be based on the respect for fellow human beings and should take into account the beliefs and values of each person based on his or her culture.

The professional takes into account the values and perspective of the user and seeks to include them in clinical practice. ${ }^{32}$ The applicability of specific programmes requires a community approach to adapt them to meet the needs of the target population. ${ }^{33} 34$

Acknowledgements We thank Alexa Ferroni and Susagna Guardiola for helping us translate the study into English and Oscar Bueno for his initial contribution to the project.

Contributors NCA and CML conceived the study and wrote the first draft of the manuscript. $A B$ and EPR contributed to the development of ideas, the design of the study and the final manuscript. MAL and MVM participated in correcting the final protocol study and the final manuscript. All the authors read and approved the final version of the manuscript and were involved in conducting the study.

Funding This study was supported by Projecte Xb of the Àmbit d'Atenció Primària Barcelona Ciutat (Institut Català de la Salut).

Competing interests None.

Patient consent Obtained.

Ethics approval Clinical Research Ethics Committee (CEIC) of IDIAP Jordi Gol in Barcelona.

Provenance and peer review Not commissioned; internally peer reviewed.

Open Access This is an Open Access article distributed in accordance with the Creative Commons Attribution Non Commercial (CC BY-NC 3.0) license, which permits others to distribute, remix, adapt, build upon this work noncommercially, and license their derivative works on different terms, provided the original work is properly cited and the use is non-commercial. See: http:// creativecommons.org/licenses/by-nc/3.0/

\section{REFERENCES}

1. Bullough V, Bullough B. Prostitution: an illustrated social history. New York: Crown Publishers, 1978.

2. Jennes V. From sex as sin to sex as work: COYOTE and the reorganization of prostitution as a social problem. Soc Probl 1990;37:403-20.

3. UNAIDS. AIDS scorecards overview: UNAIDS report on the global AIDS epidemic 2010. UNAIDS [47 p] 2011. http://www.unaids.org/ en/media/unaids/contentassets/documents/unaidspublication/2011/ 20111130_UA_Report_en.pdf

4. WHO. HIV/AIDS sex work toolkit. WHO, 2012. http://www.who.int/ hiv/topics/vct/sw toolkit/en/

5. WHO. Sex work-key facts and figures. WHO, 2012. http://www. who.int/3by5/en/factsheet.pdf

6. UNAIDS. UNAIDS Guidance Note on HIV and Sex Work. UNAIDS 2012. http://data.unaids.org/pub/basedocument/2009/JC2306_ guidance note hiv and sexwork en.pdf

7. Hernández Avila $M$, Uribe Zuniga $\bar{P}$, De Zalduondo BO. Diversity in commercial sex work systems: preliminary findings from Mexico city and their implications for AIDS interventions. In: Chen LC, Amor JS, Segal SJ, Anderson JM, eds. AIDS and women's reproductive health. Plenum Press, 1991:179-94.

8. Ngugi EN, Plummer FA, Simonsen JN, et al. Prevention of transmission of human immunodeficiency virus in Africa: effectiveness of condom promotion and health education among prostitutes. Lancet 1988;2:887-90.

9. CEEISCAT. Monitorización de la prevalencia del VIH y las ITS. CEEISCAT 2010. http://www.ceescat.org/Documents/SIVES/ SIVES2010CAST_monitorizacion_prevalencia.pdf

10. Agència de Salut Pública de Barcelona. Morbiditat per malalties de declaració obligatòria a Barcelona ciutat. Agència de Salut Pública de Barcelona 2011. http://www.aspb.es/quefem/docs/Morbiditat_ 2008.pdf

11. Folch C, Sanclemente C, Esteve A, et al. Diferencias en las características sociales, conductas de riesgo y prevalencia de infección por el virus de la inmunodeficiencia humana e infecciones de transmisión sexual entre trabajadoras del sexo españolas e inmigrantes en Cataluña. Med Clin (Barc) 2009;132:385-8.

12. Rational Choice and Risk Research. Learning about risk. Canterbury: SCARR Launch Conference, 2005.

13. Zinn JO. Sociology and Risk. Social Contexts and Responses to Risk (SCARR). 2004. http://www.kent.ac.uk/scarr/publications/ Sociology\%20Literature\%20Review\%20WP1.04\%20Zinn.pdf

14. Zinn JO. Health, risk and uncertainty in the life course: a typology of biographical certainty constructions. Soc Theory Health 2004;2:199-221. http://www.palgrave-journals.com/sth/journal/v2/n3/ abs/8700033a.html

15. Taylor-Gooby $P$, Zinn JO. Current directions in risk research: new developments in psychology and sociology. Risk Anal 2006;26:397-411.

16. Fisher JD, Fisher WA. Changing AIDS-risk behavior. Psychol Bull 1992:111:455-74.

17. Rosenstock IM, Strecher VJ, Becker MH. Social learning theory and the Health Belief Model. Health Educ Q 1988;15:175-83.

18. Bandura A. Self-efficacy: toward a unifying theory of behavioral change. Psychol Rev 1977;84:191-215.

19. Bandura A. Perceived self-efficacy in the exercise of control over AIDS infection. Eval Program Plann 1990;13:9-17.

20. Ajzen I, Fishbein M. Understanding attitudes and predicting social behavior. 1st edn. Prentice-Hall, 1980.

21. Ajzen I. Attitudes, personality and behavior. Cengage Learning, 1988

22. Ajzen I. The theory of planned behaviour: reactions and reflections. Psychol Health 2011;26:1113-27.

23. Aragon-Diez J. Programa de investigación sobre las trabajadoras sexuales como vector de propagación del VIH en el área venezolana de la frontera con la república de Colombia. Aldea Mundo 2001;4:47-52.

24. Aragón-Diez J. Variables cognitivas y conducta de riesgo de infección por VIH en trabajadoras sexuales de San Cristóbal, Táchira. Aldea Mundo 2004;8:60-70.

25. Amaro Quintas AM. Triplemente vulnerabilizadas. Prostitutas, inmigrantes y transexuales. Vulnerabilidad en la salud, servicios de salud y contextos. Universidad de Alicante (UIDESP), editor. 2010.

26. Berenguera A, Almeda J, Violan C, et al. Perception of the risk of HIV-AIDS infection of users by Non-Governmental Organisations (ONGs) who work in prevention-control of HIV-AIDS in Catalonia. Aten Primaria, 2012.

27. Amaya A, Canaval GE, Viáfara E. Estigmatización de las trabajadoras sexuales: influencias en la salud. Colombia Médica 2005;36(3 Suppl 2):65-74.

28. Bruce E, Bauai L, Sapuri M, et al. HIV knowledge, risk perception, and safer sex practices among female sex workers in Port Moresby, Papua New Guinea. Int J Womens Health 2011;3:53-61.

29. Umar US, Adekunle AO, Bakare RA. Pattern of condom use among commercial sex workers in Ibadan, Nigeria. Afr J Med Med Sci 2001;30:285-90.

30. Conde F. Los grupos triangulares como espacios transicionales para la producción discursiva: un estudio sobre la vivienda en Huelva. In: Gordo AJSerrano A. eds. Estrategias y prácticas cualitativas de investigación social. Madrid: Pearson Educación, S.A, 2008:153-88. 
31. Íñiguez Rueda L. El análisis del discurso en las ciencias sociales: variedades, tradiciones y prácticas. Análisis del discurso. Manual para las ciencias sociales. Barcelona: Editorial UOC, 2006:89-128.

32. Ruiz MR, Rodriguez JJ, Epstein R. [What style of consultation with my patients should I adopt? Practical reflections on the doctor-patient relationship]. Aten Primaria 2003;32:594-602.
33. Conviser R. Catalyzing system changes to make HIV care more accessible. J Health Care Poor Underserved 2007;18:224-43.

34. Rhodes SD, Hergenrather KC, Wilkin A, et al. Preventing HIV infection among young immigrant Latino men: results from focus groups using community-based participatory research. $J$ Natl Med Assoc 2006;98:564-73. 